\title{
Note on a Specimen of Echinorhinus spinosus.
}

\author{
By
}

F. B. Stead, B.A.

A SPECIMEN of this somewhat uncommon shark was recently brought to the Laboratory by some fishermen. The following notes on it may be of interest. The fish was taken with a long line baited with mackerel, for conger. It was captured forty miles south of the Mewstone, at a depth of about forty-five fathoms. The specimen was a female, and measured 6 feet 6 inches from the end of the snout to the tip of the tail. The following are the principal other measurements: snout to anterior edge of first dorsal fin, 46 inches; snout to anterior edge of pectoral, 20 inches; the interval between the anterior edge of the pectoral and the pelvic fin was 26 inches. The first dorsal, which was small, was thus situated immediately above the pelvic. The second dorsal, which was smaller than the first, was situated as nearly as possible midway between the first dorsal and the commencement of the caudal fin. The measurements so far tally with Day's description of the species.

Attention may, however, be drawn to the measurements which follow in connection with the following statement in Day: "Ventral (fin) . . . commences mid-way between the front gill opening and the end of the caudal fin in elongated forms: or anterior end of the snout and middle of the caudal fin, as observed in the Plymouth and Aberdeen stouter specimens." (Day's British Fishes, vol. ii. p. 323.)

In my specimen the distance from the front gill opening to the anterior edge of the ventral was 30 inches: thence to the end of the caudal was 33 inches. On the other hand, the distance of the anterior edge of the ventral to the middle of the caudal was 26 inches, and to the end of the snout was $44 \frac{1}{2}$ inches.

It will be seen that my specimen corresponds to one of the "elongated forms," and not to the "stouter specimens," said to have been observed in Plymouth. Considering the relatively small number of specimens of this shark which have been captured and measured, the 
distinction between the elongated and stouter forms is perhaps hardly justified, and the measurements above recorded show that Plymouth specimens do not invariably belong to the latter class.

In other respects my notes as to the external features of the fish agree with Day's description.

- The specimen was sent to the Museum of Zoology at the University of Cambridge, and I am indebted to Mr. S. F. Harmer for the following further facts in connection with it:

The ovaries were undeveloped : there were no large ovarian eggs, and the oviducts were quite small.

It should be noticed in this connection that the specimen was probably not full-grown. Day speaks of a female 9 feet long, containing 17 eggs, as having been taken off the Eddystone, and mentions a male 6 feet 2 inches long "having two large lobes of milt."

In various parts of the alimentary canal specimens were found of the parasite Distomum insigne. Several of these were attached to the roof of the pharynx; two were in the stomach, and appeared to be partially digested; one was in the small intestine, and several among the turns of the spiral valve. The alimentary canal contained nothing else except some glairy material and a few Isopods belonging to the species Conilera cylindracea (Montagu). One of these was in the stomach, and alive, though very sluggish; the others were in the large intestine, in the folds of the spiral valve, and appeared to be partially digested. There was nothing else recognisable in the alimentary canal.

In some of the specimens referred to by Day, it is stated that dogfishes were found in their stomachs, and in one specimen there were no fish, but remains of Crustacea. Day further quotes a suggestion made by Mr. Cornish, that there are two permanent varieties of this shark" one a ground -shark: the other a round or swimming." I have not been able to find the evidence on which this suggestion was based. 